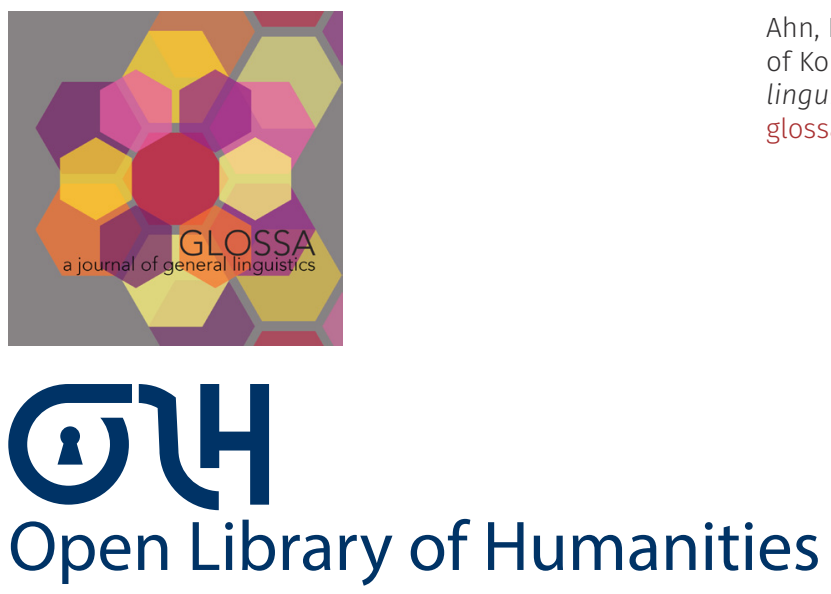

Dothy \& Koejeong. 2022. On non-conservativity of Korean floating quantifiers. Glossa: a journal of general linguistics 7(1). pp. 1-34. DOI: https://doi.org/10.16995/ glossa.5776

\title{
On non-conservativity of Korean floating quantifiers
}

Dorothy Ahn, Rutgers University, US, dorothy.ahn@rutgers.edu

Heejeong Ko, Seoul National University, KR, hko@snu.ac.kr

Since the Conservativity Universal (Barwise \& Cooper 1981; Keenan \& Stavi 1986) has been proposed for natural language determiners, several apparent counterexamples have been presented in the literature. Some of these, such as English only in Only students presented, have been argued to involve an adverbial structure, thus not violating Conservativity. In this paper, we focus on proportional quantifiers such as $70 \%$ in Korean, which have been shown to have a nonconservative reading when floated out of the DP (Ahn \& Sauerland 2017). While Ahn \& Sauerland (2017) assume that floated quantifiers are adnominal, Korean floated quantifiers have been shown to have both adnominal and adverbial variants (Ko 2014), thus leaving open the possibility that the non-conservative reading is simply resulting from an adverbial structure, like only. We test out the predictions of the adnominal and the adverbial accounts of non-conservative quantifiers in Korean. Our results show that floating quantifiers in non-conservative contexts a) cannot be definite-marked, and b) cannot be intervened by a vP-internal (low) adverbial, both of which are predicted if the non-conservative quantifier is adnominal, but not if it is adverbial. Based on these findings, we conclude that the non-conservative proportional quantifiers in Korean involve adnominal floating quantifiers. Our study thus makes a novel case for the claim that syntactic movement can be implicated in order to explain a non-conservative construal of a quantifier in languages under the Conservativity Universal.

Glossa: a journal of general linguistics is a peer-reviewed open access journal published by the Open Library of Humanities. (c) 2022 The Author(s). This is an open-access article distributed under the terms of the Creative Commons Attribution 4.0 International License (CC-BY 4.0), which permits unrestricted use, distribution, and reproduction in any medium, provided the original author and source are credited. See http://creativecommons.org/licenses/by/4.0/. 


\section{Introduction}

The Conservativity Universal (Barwise \& Cooper 1981; Keenan \& Stavi 1986) states that all generalized quantifiers that are expressed by a determiner in a natural language are conservative, where conservativity is defined as in (1).

(1) A quantifier $Q \in D_{<\mathrm{et},<\mathrm{et}, \mathrm{t}>>}$ is conservative if and only if for all $\mathrm{X}, \mathrm{Y} \subseteq \mathrm{U}, \mathrm{Q}(\mathrm{Y})(\mathrm{X})=1$ iff $\mathrm{Q}(\mathrm{Y})(\mathrm{X} \cap \mathrm{Y})=1$.

What this entails is that quantifiers like every, most, and less than seven only take into account the cardinality of the restrictor set and the intersection between the restrictor set and the scope set: in Some students came to class, the only relevant sets are the ones defined within the restrictor set, namely the set of students and the students who came to class.

There are, however, apparent violations of the generalization. For example, only in a determiner position as in (2) has been argued to violate the Conservativity Universal since it necessarily refers to the set of smokers who are not students (see von Fintel \& Keenan 2018 for discussion).

Only students smoke.

Another determiner that has been pointed out as violating the Conservativity universal is many, as discussed in examples like (3) in Westerståhl 1985. Here, too, there is a reading available that is not conservative: in that reading, the sentence is true if and only if many of the Nobel Prize winners in literature are Scandinavians.

Many Scandinavians have won the Nobel Prize in literature.

Both Westerståhl (1985) and Cohen (2001) analyze many as making a reference to the cardinality of the scope set, and thus argue that these expressions are non-conservative. Zuber (2004) argues that some complex determiners in Polish are non-conservative. Thus, there is an open question on whether Conservativity holds universally, and if not, how it should be modified (see von Fintel \& Keenan 2018 for detailed discussion on the current status of the universal).

In response to these apparent counterexamples, two approaches have been taken to retain the strong form of the universal. The first is to argue that these expressions are not actually determiners and thus not subject to the Conservativity Universal (von Fintel 1997; Heim \& Kratzer 1998; Romero 2015). For example, only is argued to be an adverb, and many is argued to be a gradable adjective. Based on the analysis of only, we will call this approach the adverbial approach. The second is to argue that these expressions are indeed adnominal determiners, and Conservativity does hold for these expressions, but not strictly in the syntactically-determined 
way. For example, Herburger (1997) argues that the first argument of non-conservative quantifiers like many and few is provided contextually via a focus-operator. Ahn \& Sauerland (2017) focus on proportional quantifiers such as $70 \%$ and argue that the non-conservative variants have a different internal structure that causes the number phrase to quantifier-raise (QR). We will call these the adnominal accounts of non-conservative quantifiers.

While both of the adnominal accounts propose that there is some sort of a movement of the measure phrase that derives the non-conservative reading, the movement is not overtly reflected in the surface structure in the languages discussed. For example, d-raising proposed in Herburger 1997 does not result in a different surface order from the conservative counterpart, and most of the languages discussed in Ahn \& Sauerland 2017 are also assumed to have covert QR at LF. There is one language that Ahn \& Sauerland (2017) discuss that is argued to provide overt evidence for QR: Korean. Korean has been observed to mark scope overtly (Beck \& Kim 1997), and the non-conservative construal in Korean necessarily involves an overt movement of the quantifier out of the DP.

In this paper, we reevaluate the argument in Ahn \& Sauerland 2017, specifically that the floating quantifier (FQ) structure involved in non-conservative construals in Korean is due to movement of the quantifier out of the nominal domain. This is because Korean floating quantifiers have been observed to have both adnominal and adverbial variants, where the latter is basegenerated in the VP domain. Teasing apart the two kinds of floating quantifiers is crucial because it might turn out that the strongest evidence for the adnominal approach to non-conservative quantifiers is in fact an adverbial. Moreover, there is previous work on Korean proportional quantifier taypwupwun ('most/mostly') which argues that it is adverbial (Park 2007). Thus, it is still an open question whether the floating proportional quantifiers result in non-conservative readings because they are adverbials or because they involve a movement out of the DP. Thus, our goal in this paper is to determine whether floating quantifiers involved in non-conservative construals in Korean are adnominal or adverbial in their underlying forms.

In order to determine whether floating proportional quantifiers in Korean are adverbial or adnominal, we identified two different diagnostics and implemented them into two online truth-value judgment (TVJ) tasks. First, we looked at the definiteness effect on the host noun, the noun that is syntactically in the restrictor position. If the determiner moves out of the DP leaving the host noun stranded, either at LF or overtly, we would expect the host noun to always be non-definite. However, if the floated quantifier is adverbial, there should not be any restriction on whether the host noun is definite or not. Thus, we tested in Study 1 whether floating quantifiers involving definite host nouns allow non-conservative readings. The results suggest that non-conservative construals are indeed restricted to non-definite host nouns, thus supporting the adnominal accounts. Second, we made use of the diagnostic presented in Ko 2014 with $v$ P-internal adverbials such as capalcekulo ('voluntarily'), which are dubbed 'low' adverbials 
(see footnote 3 for their characteristics). Ko (2014) argues that there are certain syntactic contexts where an adnominal floating quantifier cannot be licensed in Korean. One representative case involves intervention of a low adverbial. Ko claims that due to ordering restrictions imposed on $\nu \mathrm{Ps}$, low adverbials cannot intervene an adnominal floating quantifier and the host noun merged on the $v \mathrm{P}$ edge while an adverbial floating quantifier is licensed rather freely.

If proportional quantifiers with a non-conservative construal are adnominals, we predict that they will exhibit the same ordering restriction as other adnominal quantifiers in Korean. If, however, proportional quantifiers are adverbs, we predict that they will freely co-occur with low adverbs, maintaining a non-conservative reading. In Study 2, we do find intervention effects of a low adverb. The results suggest that proportional quantifiers with a non-conservative reading are adnominals in nature, which are subject to severe ordering restrictions.

The rest of the paper is organized as follows. In Section 2, we briefly overview the three approaches to non-conservative quantifiers introduced in this section. Section 3 discusses our first study on definiteness, and Section 4 discusses our second study on adverb intervention. Section 5 discusses the main findings of the two studies, and Section 6 concludes with implications and some remaining questions.

\section{Approaches to non-conservativity}

In this section, we provide a brief overview of the main approaches to non-conservative quantifiers that maintain the Conservativity Universal. The first is the focus approach, where it is argued that the non-conservative construals involve intransitive quantifiers whose restriction is provided contextually. This is proposed in Herburger 1997 in response to the 'reverse quantification' analysis proposed in Westerståhl 1985, which cannot capture the focus sensitivity of non-conservative readings of quantifiers such as few and many. The second is the QR approach proposed in Ahn \& Sauerland 2017 which argues that the non-conservative construals involve an unstable DP and a QR of the quantifier phrase. The focus approach and the QR approach together form the adnominal accounts of non-conservative quantifiers because they both maintain that the quantifier is underlyingly a determiner. The last approach we discuss is the adverbial approach, where it is argued that non-conservative quantifiers such as only or many are not underlyingly determiners and instead adverbials or adjectives, thus not subject to the universal. We will see that there is no evidence provided in previous works that reject this hypothesis, thus leaving open the possibility that the floating quantifiers in Korean are not determiners.

\subsection{Adnominal approach}

Herburger (1997) and Ahn \& Sauerland (2017) propose that the quantifier is base-generated inside the DP, and moved out of the DP. While details differ, they both argue that the displaced determiner takes a focus-generated restrictor argument, thus deriving the non-conservative reading. We discuss the two approaches below. 


\subsubsection{Focus approach}

Herburger (1997) argues against the non-conservative analysis presented in Westerståhl 1985, which is often called the 'reverse quantification' analysis. The idea in Westerståhl 1985 is that some quantifers such as many can have a reversed reading, where the restrictor and the scope arguments are switched. Thus, in the example in (3) repeated in (4), the determiner many takes the VP as the restrictor and the NP as the scope argument.

(4) Many Scandinavians have won the Nobel prize in literature.

Herburger (1997) argues against this view with the following observations. First, she shows that the non-conservative construals require focus on the host noun: the non-conservative reading is only available when the host noun is focused in (4), as in (5a), and not when the VP is focused as in (5b).

a. Many SCANDINAVIANS have won the Nobel prize in literature.

b. Many Scandinavians have won THE NOBEL PRIZE IN LITERATURE.

[Herburger 1997: (19)]

She further observes that only weak determiners, and not strong determiners, give rise to non-conservative readings. Based on these observations, Herburger (1997) argues that the weak quantifiers involved in non-conservative construals differ from strong quantifiers in the way in which they move out of the DP. Specifically, she argues that while strong quantifiers QR to take clausal scope, non-conservative quantifiers involves a head movement of the determiner D to a local landing site in T, as shown in (6a). Because D is unary in this structure, the entire VP serves as the matrix argument, and there is no syntacticallyprovided restrictor argument for D. Instead, the restrictor argument for a unary determiner is provided nonsyntactically, through association with focus. That is, the focus alternatives of the entire VP serves as the restriction of quantifier few in (6). This correctly derives the non-conservative reading that few of the entities who applied are cooks who applied as in (6b).

(6)

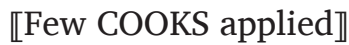

a.

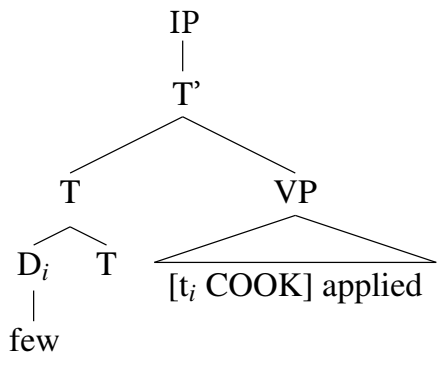

[Herburger 1997]

b. [Few x: $\exists \mathrm{P} P(\mathrm{x}) \&$ applied(x)] $\operatorname{COOKS}(\mathrm{x}) \& \operatorname{applied(x)}$

[Herburger 1997: (27-28)] 
The advantage that the focus approach has over the reverse account in Westerståhl 1985 is that it correctly derives the non-conservative reading arising from subconstituent focus. For example, if only the word incompetent is focused as in (7), the resulting reading is that few of the cooks who applied were incompetent cooks who applied. This is readily derived if the restrictor argument is formed through association with focus, but not if the restrictor argument and the scope argument are simply reversed.

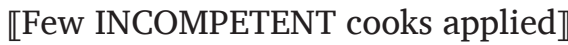

a. [Few x: cooks (x) \& applied(x) \& ᄏP P(x)] cooks(x) \& applied(x) \& INCOMPETENT(x)

[Herburger 1997: (31)]

\subsubsection{QR approach}

Ahn \& Sauerland (2017) observe that a proportional quantifier such as sixty percent has what looks like a non-conservative reading in addition to the expected conservative reading. For example, $60 \%$ can refer to the proportion of women hired at MIT over the total number of the relevant set of women as in (8a) (conservative reading) or over the total number of people hired at MIT (non-conservative reading) as in (8b).

a. MIT hired $60 \%$ of the women.

b. MIT hired $60 \%$ women.

Across languages, Ahn \& Sauerland (2017) show that the non-conservative reading is associated with focus on the restrictor noun (e.g. women in (8b)), a non-genitive case-marking (the lack of of in (8b)), and the lack of definite marking (women instead of the women in (8b)). Based on these observations, Ahn \& Sauerland (2017) argue that the two readings result from two different constituencies in the underlying structure. The two underlying structures for the conservative and the non-conservative readings are shown in (9) and (10), respectively. ${ }^{1}$

\section{Conservative}

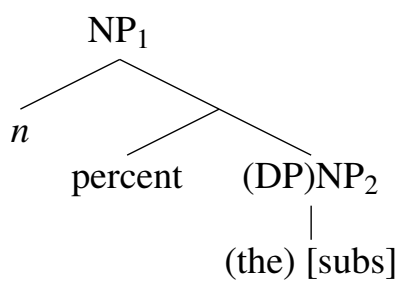

${ }^{1}$ The 'non-conservative' structure does not in fact involve a non-conservative quantifier in their analysis. But we will continue to call this reading the non-conservative construal for ease of reference. 
(10)

\section{Non-conservative}

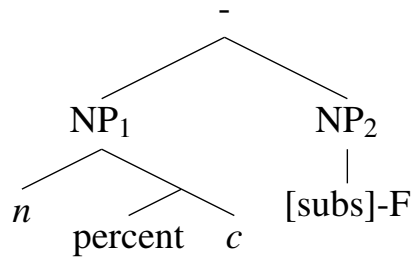

(11)

$$
\llbracket \text { percent } \rrbracket=\lambda x \in D_{e} \lambda n \in D_{d} \lambda P \in D_{e t} \cdot \frac{\mu(x \sqcap \oplus P)}{\mu(x)}=\frac{n}{100}
$$

In the conservative structure, percent as defined in (11) combines with the host noun and the numeral in a typical way, resulting in a meaning that, for some measure unit of $\mu$, the ratio of $\mu$ of the entity such that that entity is of the host noun and VP $(\mu(x \sqcap \oplus P))$ and the $\mu$ of the totality of the host noun entity is $n: 100$.

In the non-conservative structure, on the other hand, the lexical entry for percent in (11) cannot straightforwardly combine with the other arguments. In order to compose (10), Ahn \& Sauerland (2017) argue that 1) c turns into an e-type entity, 2) the measure phrase quantifier raises $(\mathrm{QR})$ to clausal scope, and c) the trace is replaced by a definite determiner of type 〈et,e〉 (modifying ideas presented in Fox 2002; Sauerland 2004). These three assumptions together successfully derive the meaning that the $n$ percent of the maximal plural individual denoted by the VP are those denoted by the host noun (See Pasternak \& Sauerland 2022 for an updated analysis of non-conservative structures that reduces some of the stipulations made in Ahn \& Sauerland 2017 and embeds the analysis in a degree-based system).

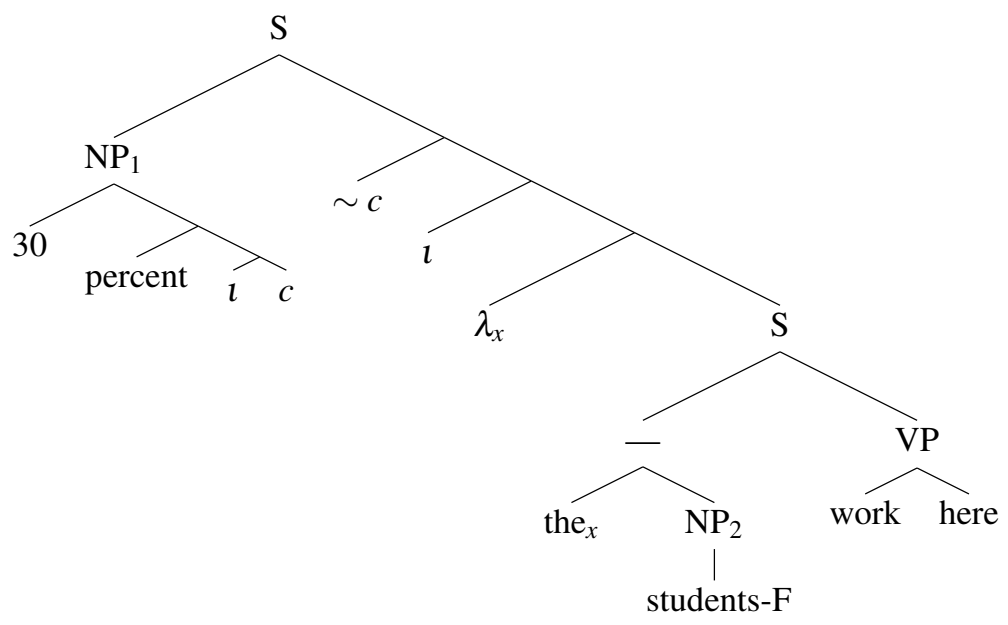




\subsection{Adverbial approach}

Lastly, it has also been argued that the counterexamples to the Conservativity Universal are not indeed counterexamples, because expressions such as only, many and few are not in fact determiners. For example, the non-conservative property of only is not taken to be a counterexample to the Conservativity Universal because only is analyzed as an adverbial (von Fintel \& Keenan 2018; von Fintel 1997). Semantic analyses of only treat it as taking the full proposition as an argument, rather than just taking the content of the NP. The question that follows is whether the nonconservative floating proportional quantifiers in Korean, and more broadly all non-conservative proportional quantifiers discussed in Ahn \& Sauerland 2017, are adverbial rather than adnominal. For example, it is possible that the proportional measure $60 \%$ in SNU hired $60 \%$ students is an adverbial that attaches in the VP and quantifies over hiring events.

In such an analysis, $60 \%$ would behave similarly to an adverbial like mostly in SNU hired mostly students. The main arguments that Ahn \& Sauerland (2017) present against this view involve showing the constituency of the DP that involves the determiner and the noun. First, for languages like English, a measure phrase like 75\% cannot be separated from the restrictor noun like mostly can.

(13) a. The company will mostly $/ * 75 \%$ hire women this year.

b. Who does the audience consist of mostly/*30\%? [Ahn \& Sauerland 2017: (18-19)]

Second, preposing $75 \%$ women is possible, which is not predicted if $75 \%$ is an adverbial because it would not form a constituent with women.

[75\% women] (I believe) the company will hire _ this year

However, these criteria are not applicable to Korean given that the non-conservative construals always involve floating quantifiers, which by definition are separated from the host noun. Ahn \& Sauerland (2017) do not provide any Korean-specific diagnostic to determine whether the floating quantifiers are indeed adnominal or not, thus leaving this option open for investigation.

Moreover, there is a related work in Korean that argues for an adverbial analysis of a non-conservative floating quantifier. Park (2007) shows that the quantifier taypwupwun ('most/mostly') allows a non-conservative reading when floated, and proposes an adverbial account. More specifically, she argues that taypwupwun should be analyzed as an adverbial quantifier that quantifies over events. For example, (15) is analyzed as (16) (modified and translated from Korean). 
(15)
haksayng-tul-i taypwupwun soselchayk-ul sa-ss-eyo.
student-PL-NOM most
novel-ACC
buy-PAST-DECL

'Most of the events of novel-buying involved students.'

[Park 2007: (20)]

(16) $\exists \varepsilon\left[\forall \mathrm{e} \in \varepsilon[\right.$ novel-buying(e) $] \wedge \exists \varepsilon^{\prime}\left[\varepsilon^{\prime} \subseteq \varepsilon \wedge\left|\varepsilon^{\prime}\right| \geq 1 / 2|\varepsilon| \wedge \forall \mathrm{e}^{\prime} \in \varepsilon^{\prime}[\operatorname{AgENT}(\mathrm{e}, \mathrm{x}\right.$.students(x))]]]

Given that there are no diagnostics provided to determine whether the floating quantifiers involved in non-conservative construals are adnominal or adverbial, and that the only other account of a non-conservative proportional quantifier analyzes it as an adverbial element, it seems crucial to confirm whether the proportional quantifier like $70 \%$ in Korean is indeed basegenerated in the nominal phrase as Ahn \& Sauerland 2017 argue.

\subsection{Research Question}

What we see is that in both of the adnominal accounts, the quantifier is argued to move out of the DP. In Herburger 1997, it is done through D-raising, and in Ahn \& Sauerland 2017, it is done through QR. In either case, movement is a crucial element of the adnominal accounts, because only after movement the quantifier combines with a focus-generated restrictor argument.

Korean is argued to provide overt evidence for movement in Ahn \& Sauerland 2017. Korean has been argued to mark scope overtly (Beck \& Kim 1997). In Korean, the non-conservative construal involves a floating quantifier structure unlike the conservative construal. This is shown in (17), where the proportional quantifier $20 \%$ appears inside the nominative-marked subject for the conservative reading in (17a), and outside the nominative-marked subject for the nonconservative reading in (17b).
a. [kyosu-(uy) isip-phulo]-ka wassta.
professor-GEN twenty-percent-NOM came
'Twenty percent of the professors came.'
(conservative)
b. $\left[\mathrm{kyosu}_{\mathrm{F}}\right]-\mathrm{ka}$ isip-phulo wassta.
professor $_{F}$-NOM twenty-percent came
'Twenty percent of those who came were professors.' (non-conservative)

Ahn \& Sauerland (2017) argue that while the $\mathrm{QR}$ of $\mathrm{NP}_{1}$ in other languages is covert, it is reflected in the syntax in Korean, thus supporting the QR-based analysis.

However, the assumption that a floating quantifier derives from a DP-internal position is not readily supported in the literature. In fact, what we observe is that the discussion is quite divided. The (non-)local dependency between a noun and a floating quantifier has been widely 
debated in the syntax literature. One of the main debates are formed around the question of whether the floating quantifier is adnominally derived, meaning that they are base-generated inside the DP and stranded from the NP, or adverbial, meaning that they are base-generated outside the DP and inside the VP. Ko (2014) argues that some languages have both adnominal and adverbial floating quantifiers, and argues that Korean is one of those languages that have both adnominal and adverbial types (see also Ishii 1998, Kang 2002, Fitzpatrick 2006, among others). ${ }^{2}$ Ko proposes that adnominal floating quantifiers are externally merged to its host NP in the base structure, as schematized in (17) (see Kuroda 1983; Sportiche 1988; Ueda 1990, a.o.). Adverbial floating quantifiers, on the other hand, contain a pro linked to the host NP and are merged outside a verbal structure, as described in (18) (see Doetjes 1997, Kobuchi-Philip 2003; 2007; Fitzpatrick 2006).

(18) Adnominal Floating Quantification $\left.\left[\mathrm{CP}_{i}\left[_{\nu \mathrm{P}}\left[\mathrm{nP}_{i} \mathrm{NQ}\right] \mathrm{O} \mathrm{V}\right]\right]\right]$

(19) Adverbial Floating Quantification $\left[_{\mathrm{TP}} \mathrm{S}_{i}\left[_{\mathrm{FocP}}\left[{ }_{\mathrm{nP}} \mathrm{FQ}\right.\right.\right.$ pro $\left.\left.]\left[\mathrm{p}_{\mathrm{vP}} \mathrm{t}_{i} \mathrm{OV}\right]\right]\right]$

Based on a range of semantic and syntactic diagnostics, Ko (2014: Chapter 3) argues that bare numeral quantifiers without focus belong to the adnominal type in Korean and that floating quantifiers with exhaustivity (e.g. Case-marked numerals, exhaustive-marked numerals, motwu 'all', NPI amwuto 'anyone') belong to the adverbial type. As far as the authors know, there is no syntactic work that investigates whether proportional quantifiers such as $70 \%$ is adnominal or adverbial underlyingly.

In order to determine whether Korean floating quantifiers in non-conesrvative construals involve adverbials or adnominals, we designed two experimental tests based on different diagnostics. In the first study, we test whether the host noun can be definite-marked, based on our reasoning discussed above that adnominal quantifiers would not allow definite host nouns. In the second study, we test whether non-conservative reading is possible when a floating quantifier

\footnotetext{
${ }^{2}$ Ishii (1998) argues that floating quantifiers are ambiguous between an adnominal quantifier and an adverbial Q, and that systematic counterexamples to the adnominal quantifier approach are limited to cases in which floating quantifiers bear a distributive reading, which should be analyzed as adverbial. Kang (2002) argues that floating quantifiers in Korean can be used as a verbal modifier in a context where quantificational information is in focus. Fitzpatrick (2006) shows that exhaustivity is systematically correlated with a quantifier type, in such a way that only adverbial quantifiers bear the semantics of exhaustivity. Fitzpatrick (2006) also argues that adverbial floating quantifiers are characterized by A-movement of the associate noun, whereas adnominal floating quantifiers are diagnosed by A'-movement of the host noun (a summary taken from Ko 2014:73).
} 
is separated from the host noun by a low adverb, which is a diagnostic for identifying adnominal floating quantifiers presented in Ko 2014. Because differentiating between conservative and non-conservative construals requires identifying subtle differences in interpretation, we tested our target sentences against a larger number of participants in a systematically controlled experimental setting.

\section{Study 1: Restriction on definiteness}

The first diagnostic that we used to tease apart the adverbial account and the adnominal account involves the status of the host noun. Adnominal accounts require that the host noun be nondefinite, because the determiner has moved out of the DP. In Herburger 1997, the determiner D-raises locally, leaving the noun stranded, while in Ahn \& Sauerland 2017, the n-percent-c constituent QRs to take clausal scope, leaving a definite trace that must combine with the host noun. Thus in both accounts, the host noun must not itself be a definite element due to type and selectional restrictions. On the other hand, an adverbial quantifier does not have such restrictions and allows definite-marked host nouns as shown in (20).

a. Only the students came.

b. The students applied mostly.

Thus, if the floating quantifier structure in Korean is a result of an adnominally derived quantifier, we would expect to see the same restriction on definite host nouns. Specifically, we would expect the non-conservative reading to be impossible when the host noun is definite. Alternatively, if the floating quantifier is an adverbial, then we would not expect to see any sensitivity to the definiteness of the host noun: non-conservative reading would be possible regardless of whether the noun is definite or not.

Korean does not have an overt definite marker. Bare nouns in Korean can encode both definite and indefinite meanings (Lee 1992, a.o.). This means that we cannot simply add a definite marker to ensure a definite reading and an indefinite marker to ensure an indefinite reading as in English. In order to control the reading of the bare noun in the experiment, we made use of the anaphoric demonstrative $k u$ and number marking. We discuss below how the demonstrative and number marking indirectly restrict the available reading of the bare noun.

\subsection{Demonstratives and plural marking}

Korean has a three-way distinction in demonstratives (Sohn 1994): $i$ is a proximal demonstrative used to pick out entities close to the speaker, while ce is a distal demonstrative used to pick out 
entities far from both the speaker and the hearer. The third demonstrative $k u$ is also traditionally analyzed as a distal demonstrative that picks out an entity present in the context, but more recent studies show that $k u$ is an anaphoric marker (Ahn 2017; Ahn \& Davidson 2018; Cho 2016): it requires the addressee to be familiar with the intended referent. The notion of familiarity that we use here requires the entity to have been previously mentioned in the discourse, which we call strong familiarity following Roberts 2003. This term contrasts with the broader term weak familiarity, which also includes entities that have not been mentioned previously but nevertheless familiar to the addressee (Roberts 2003). For example, in (21), the sentence would be unacceptable if the book in question has not been previously mentioned and established in the discourse. Thus, the insertion of $k u$ allows us to restrict the host noun to an anaphoric, definite reading.

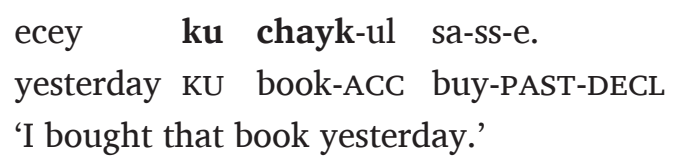

There is another phenomenon that interacts with definiteness in Korean, which is number marking. Korean is a generalized classifier language that makes use of classifiers to individuate nouns into countable units. However, unlike other classifier languages like Mandarin and Japanese, it has a productive plural marker tul that can combine with nouns to imply plurality. Studies have shown that the plural marker is obligatory when associated with definite readings (Kim 2005; Ahn \& Snedeker 2021; Kwon \& Zribi-Hertz 2004). For example, plural marking on chaeg ('book') is obligatory if it is anaphorically referring to a previously introduced book in (22).

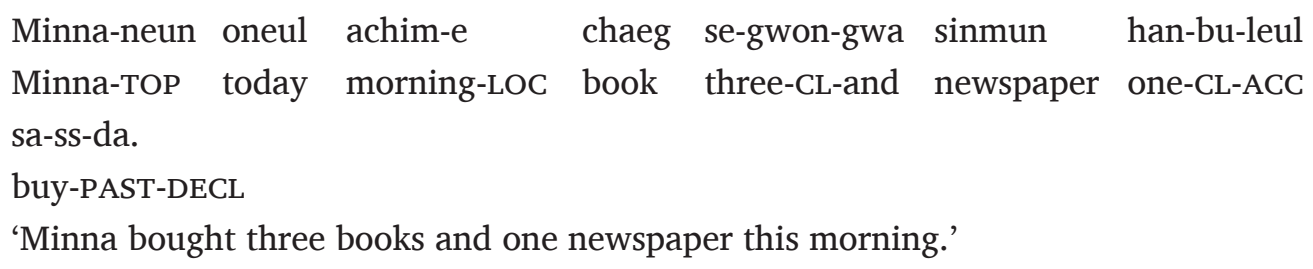

[Kwon \& Zribi-Hertz 2004]

Summarizing the two points above, there are two grammatical properties that indirectly mark definiteness: the anaphoric demonstrative $k u$ and plural marking. These two mechanisms can be combined to form a minimal pair of sentences that only differ on whether the noun is interpreted as definite or not. Consider the two sequences below: 
$(23)$

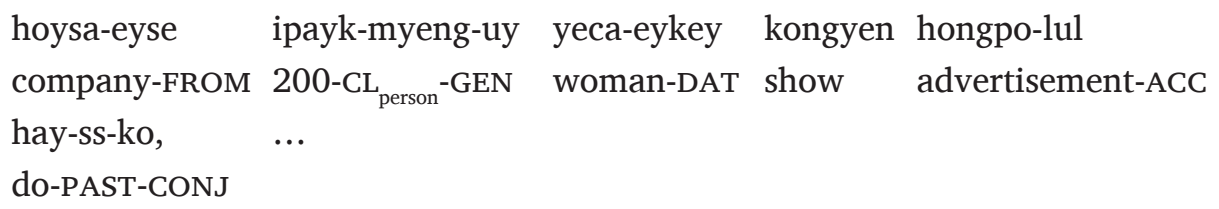

'The company advertised the show to 200 women, and ...'

a. kongyen-ey ku yeca-tul-i sasip-myeng chamsekhay-ss-ta.

show-DAT KU woman-PL-NOM 40-CL person $_{\text {attend-PAST-DECL }}$

'Forty of those women attended the show.'

b. kongyen-ey yeca-ka sasip-myeng chamsekhay-ss-ta.

show-DAT woman-NOM 40-CL person $_{\text {attend-PAST-DECL }}$

'Forty women attended the concert.'

The first sentence introduces a discourse referent of two-hundred women who received the company advertisement. The only difference between (23a) and (23b) is that while the former contains a demonstrative description with a plural marker $k u$ yeca-tul ('those women'), the latter only involves a bare noun yeca ('woman'). The continuation in (23a) is restricted to a definite, anaphoric reading, where ku yeca-tul refers to the women mentioned in (23): (23a) asserts that forty of those women attended the show. On the other hand, (23b) can only have an indefinite reading that there exist forty women who attended the show, with no implication that the forty women are associated with the discourse referent introduced in (23). Even though the setup of the example pragmatically makes an anaphoric continuation more likely, a definite reading of the bare noun in (23b) is impossible because plural marking is absent: if interpreted as a definite, the absence of the plural marker in (23b) would suggest that there is only one salient woman, but that reading is incompatible with the cardinality of forty that follows.

Note that it is possible to only have the plural-marked noun without the demonstrative as in (24), but in that case, the meaning is ambiguous between a definite and an indefinite construal. In order to avoid this ambiguity, we focused only on sentences like (23a) and (23b).

$$
\begin{aligned}
& \begin{array}{l}
\text { kongyen-ey yeca-tul-i sasip-myeng } \\
\text { show-DAT }
\end{array} \text { woman-PL-NOM } 40-\mathrm{CL}_{\text {person }} \text { attend-PAST-DECL } \\
& \text { '\{Forty of those women / Forty women } \text { attended the show.' }
\end{aligned}
$$

\subsection{Conditions and predictions}

By replacing the absolute cardinal forty to a proportional measure like $40 \%$, we are able to construct a minimal pair of sentences that only differs on whether a definite reading of the host noun is available. To test whether definiteness of the host noun affects the availability of the non- 
conservative reading as the adnominal accounts predict, we created an experimental stimuli with a $2 \times 2$ design between two factors: a) whether the host noun was marked as definite with both a demonstrative and plural marking $([ \pm \mathrm{DEF}])$, and $\mathrm{b})$ whether the proportion was compatible with a conservative or the non-conservative reading $([ \pm \mathrm{CON}])$ given a context. This created a total of four conditions: [ + DEF, $+\mathrm{CON}],[+\mathrm{DEF},-\mathrm{CON}],[-\mathrm{DEF},+\mathrm{CON}]$, and [-DEF,-CON].

In the study, we presented the target sentences with a context that allowed the participant to determine whether the given cardinality in the target sentence was a proportion from the total set denoted by the host noun (a conservative reading) or from the total set denoted by the predicate in the VP (a non-conservative reading). For example, for each of the four trials, participants first read the context in (25). For convenience, we provide the English translation of the Korean sentences.

(25) Context: This year my company evaluated the effect that email marketing has on the attendance at an end-of-the-year show. A total of 400 people received an email advertisement from the company, 200 of them men and 200 of them women. A total of 100 people attended the show, 20 of them men and 80 of them women.

Below the context, one of four target sentences was presented to the participant. All four target sentences started with the sentence in (26), followed by one of the four sentences in (27). In the $[+\mathrm{DEF}]$ conditions, the host noun appeared with a demonstrative description and plural marking, while in $[-\mathrm{DEF}]$ conditions, a bare noun was used. In the $[+\mathrm{CON}]$ conditions, the proportion used was $40 \%$, while in [-CON], it was $80 \%$. This is because the conservative reading in (27) would compare the number of women who attended the show to the number of women who received advertisement $(80 / 200 ; 40 \%)$, while the non-conservative reading would compare the same number to the total number of people who attended the show (80/100; 80\%).

(26) hoysa-eyse ipayk-myeng-uy yeca-eykey kongyen hongpo-lul hay-ss-ko, company-FROM 200-CL person -GEN woman-DAT show ad-ACC do-PAST-CONJ ... 'The company advertised the show to 200 women, and ...'

(27) ... kongyen-ey [host noun]-i N-phulo chamsekhay-ss-ta.

... show-DAT host noun-NOM N-percent attend-PAST-DECL

'... N percent of \{the women / women\} attended the show.'

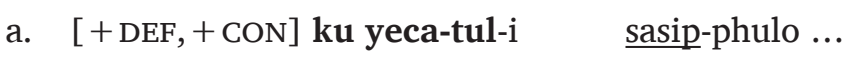

KU woman-PL-NOM 40-\%

b. $[+\mathrm{DEF},-\mathrm{CON}]$ ku yeca-tul-i phalsip-phulo ...

KU woman-PL-NOM $80-\%$ 
c. $[-\mathrm{DEF},+\mathrm{CON}]$ yeca-ka sasip-phulo ...

woman-NOM 40-\%

d. $[-\mathrm{DEF},-\mathrm{CON}]$ yeca-ka phalsip-phulo ...

woman-NOM $80-\%$

After reading one of the target sentences, the participant was asked to judge whether the target sentence was true or false given the context in (25). If there is a restriction against definitemarked host noun, we would predict (27a) to be judged to be true and (27b) to be judged as false. The hypothesis does not make a specific prediction for the $[-\mathrm{DEF}]$ conditions in $(27 \mathrm{c})$ and (27d): both conservative and non-conservative construals should be available in principle.

This prediction aligns with the authors' judgments. Given the context in (25), (27a) is judged to be true, and (27b) is judged to be false, as both sentences only allow a conservative reading. With the non-definite marked host nouns, the authors judge (27d) to be true: it readily allows the non-conservative reading where $80 \%$ of those who came were women. It is unclear to the authors whether (27c) readily allows the conservative reading as well. While the conservative reading should be available in principle, it is not salient, and some sort of a contrast is required to allow the conservative reading.

Because the judgments are subtle, some noise and interspeaker variation are unavoidable in the data. However, we looked for statistically significant contrasts across conditions and made conclusions based on such contrasts.

\subsection{Participants and Method}

Sixty-one native, monolingual speakers of Korean participated in the study. They were recruited by advertising on the campus of Seoul National University in Seoul, Korea, with flyers and on social media. The participants were asked to complete an online survey created through PCIbex (Zehr \& Schwarz 2018). After Study 1 on definiteness was complete, they were given an option to proceed to Study 2 on adverbs. Two participants were removed from the analysis because they participated in the survey twice.

The study was conducted online at the participants' respective homes. Three background questions were asked at the beginning of the survey: age (in decades), dialect of Korean used (Chuncheon, Gyeongsang, Jeju, Jeolla, and Seoul/Kyungki), and English exposure (native, fluent, some familiarity, and none). After the background survey, they were instructed to read the stimuli consisting of the context in (25) followed by the target in (26) with one of the four target variations in (27), and respond whether the target sentence in (27) is true or false.

There were a total of four test trials and four filler trials. The conditions were organized in a Latin-square design for a within-subject study, so each participant saw one of the four conditions once. A screenshot of a trial is shown in Figure 1. 
이번에 우리 회사에서 주최한 연 말 공연 이메일 마케팅 효과를 알아봤다.

회사로부터 공연 관련 이메일을 받은 사람은 총 400 명으로 그 중 남자는 200 명, 여자는 200 명이었다. 공연에 온 사람은 총 100 명으로, 남자 20 명, 여자 80 명이었다.

희사에서 200명의 여자에게 공연 홍보를 했고, 연말 공연에 그 여자들이 $40 \%$ 참석했다.

참

거짓

Figure 1: A screenshot of a trial in the $[+\mathrm{DEF},+\mathrm{CON}]$ condition (English translation of the context and the target can be found in (25), (26), and (27)).

\subsection{Results}

The participants' responses in each trial were coded as ' 1 ' for 'true' and ' 0 ' for 'false'. With the Latin-Square design and four groups, there were 11 to 20 responses per trial, with a total of 58 responses per each of the four conditions. A generalized linear mixed-effects model (GLMM) was used for the analysis, with construal and definiteness as fixed effects and group, participant, and item as random effects. The average proportion of 'true' responses by Construal (conservative vs. non-conservative) and Definiteness of host noun (definite vs. non-definite) is plotted with standard errors in Figure 2. There was a main effect of construal: participants were significantly more likely to respond 'true' in the $[+\mathrm{CON}]$ condition, i.e. when the proportional measure was compatible with the conservative construal $(Z=2.006, p=0.04)$. There was also a significant interaction between Construal and Definiteness $(Z=4.767, p<0.001)$. In the conservative conditions, participants were significantly more likely to respond 'true' when the host noun was definite $(89 \%[+\mathrm{DEF}]$ vs. $59 \%[-\mathrm{DEF}] ; Z=3.352, p<0.001)$, while in the non-conservative conditions, they were significantly less likely to respond 'true' when the host noun was definite (40\% [-DEF] vs. $10 \%[+\mathrm{DEF}] ; Z=-3.385, p<0.001)$.

\subsection{Discussion}

First, we note that the acceptance rates for the two non-definite conditions are at around $50 \%$. This is very different from the rates in the definite conditions, where there is a clear indication of accepting the conservative construal and rejecting the non-conservative construal. Because participants only saw one test item in each condition, the near-50\% rate does not suggest that 
participants were responding at random. Instead, this suggests that $40 \%$ of the participants $(24 / 58)$ responded 'true' in the [-DEF,-CON] condition, while $60 \%$ responded 'false' in the same condition. As an anonymous reviewer pointed out, participants are biased towards true construals of ambiguous sentences when they are available. Assuming this is the case, we would expect the acceptance rate of the [-DEF,-CON] condition to be at-ceiling if the reading is available. The near-50\% acceptance rate thus does not definitively demonstrative the availability of the nonconservative construal with floating quantifiers for all Korean speakers. In order to test whether the results are actually indicative of interspeaker variation or due to general confusion in the [-CON] conditions, a follow-up with more items per condition, or with a third 'I don't know' option as the reviewer suggested, would be necessary. The weaker conclusion we can draw from this set of data for now is that the non-definite-marked noun is not as systematically rejected as the definite-marked noun in the non-conservative context.

As for the effect of definiteness, the adnominal and the adverbial accounts made different predictions. The adnominal account predicted the $[+\mathrm{DEF},-\mathrm{CON}]$ condition to be rejected, while [-DEF,-CON] condition to be accepted. This prediction is borne out: participants reliably rejected [+DEF,-CON] condition (acceptance rate 10\%), while they accepted [-DEF,-CON] at a significantly higher rate at $40 \%$. This difference was not predicted in the adverbial account, because adverbial quantifiers do not restrict host noun type.

We further find that the conservative reading is available in sentences containing a nondefinite bare noun, with participants judging the sentence to be true $59 \%$ of the time. There are a couple of ways in which the conservative reading can be derived under the adnominal accounts. First, because focus generates the content of the restriction, an interpretation equivalent to a conservative construal is possible if the VP is focused. It could be argued that the participants took the target sentence in this condition to be VP-focused, resulting in the conservative reading. The possibility of deriving a conservative reading by focusing VP is discussed in both Herburger 1997 and Ahn \& Sauerland 2017. Second, the floating quantifier could have been treated as a case-marked floating quantifier. This is possible because in Korean, case markers can be dropped optionally. We discuss the ambiguity between conservative and non-conservative construals further in Section 6.2.

In summary, the results of Study 1 show that when the host noun is definite, a floating quantifier cannot receive a non-conservative reading in Korean. This is predicted if the nonconservative construal results from an adnominally-derived quantifier, but not if it results from an adverbial quantifier. Thus, our results support the adnominal account of non-conservative quantifiers. 


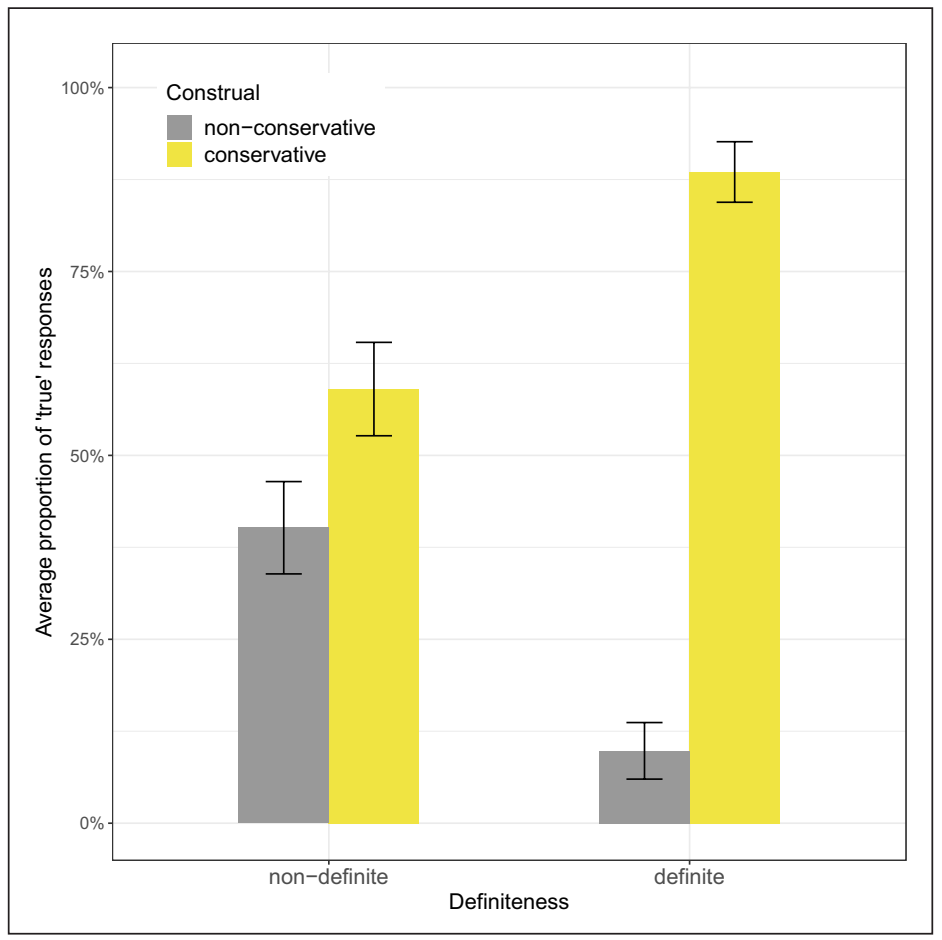

Figure 2: Average proportion of 'true' responses by Definiteness and Construal (bars: SE).

\section{Study 2: Low adverbials}

The goal of our second study was to apply an independently-motivated diagnostic for teasing apart adnominal floating quantifiers from adverbial floating quantifiers in Ko 2005; 2014 to proportional quantifiers. These diagnostics have been specifically designed and tested empirically in Korean, thus providing a reliable test for determining the syntactic nature of the non-conservative proportional floating quantifiers. The diagnostic we will focus on in this paper is that of adverb intervention. We first discuss the diagnostic in Section 4.1, and then present our second study.

\subsection{Adverbial vs. Adnominal Quantifiers: Diagnostics}

It has been extensively argued by Ko $(2007 ; 2014)$ that sub-extraction out of syntactic edges is severely restricted and underlying constituency makes a crucial difference in sub-extraction. In particular, elements merged as a constituent on syntactic edges of a cyclic domain cannot be separated by their domain-mate. This ordering restriction is called the Edge Generalization (EG), stated in (28). The EG results from a conspiracy of cyclic linearization (Fox \& Pesetsky 2005) and locality constraints on movement. If two elements, $\mathrm{X}$ and $\mathrm{Y}$ are externally merged on the syntactic edge, they cannot move around within the Spell-out domain (under Chomsky 2001 for probe-goal Search), so that $\mathrm{X}$ and $\mathrm{Y}$ may be followed or preceded by their domain-mate Z, but 
they cannot be intervened by $\mathrm{Z}$. This ordering restriction holds throughout the derivation due to cyclic linearization, which maintains the monotonicity of orderings after Spell-out.

(28) Edge Generalization (Ko 2014: 24)

If $\mathrm{X}$ and $\mathrm{Y}$ are dominated by a specifier $\gamma \mathrm{P}$ of a Spell-out domain $\alpha \mathrm{P}, \mathrm{X}$ and $\mathrm{Y}$ cannot be separated by an $\alpha \mathrm{P}$-internal element $\mathrm{Z}$ that is not dominated by $\gamma \mathrm{P}$.

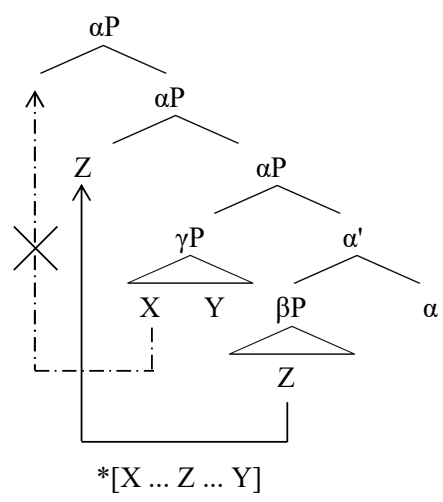

Ko (2014) presents supporting evidence for the EG, based on sub-extraction and (re)-ordering patterns out of syntactic edges in predicational domains in Korean and Japanese. Some well-known restrictions on the distribution of the subject and an adnominal quantifier can be understood as an instance of the EG. The subject and a bare numeral in Korean cannot be separated by their $\nu \mathrm{P}$-domain mate such as the object, as illustrated by the contrast between (29a) and (29b). The bare noun also cannot be separated from the subject by a $v$ P-internal (low) adverbial as shown in (30a). The subject and the adnominal quantifier are merged in the specifier of a Spell-out domain $v \mathrm{P}$, and thus they cannot be separated by a $v \mathrm{P}$-internal element within $v \mathrm{P}$, and this ordering restriction is preserved under cyclic linearization. A $v$ P-external high adverbial, on the other hand, may intervene between the subject and its adnominal Q, as shown in (30b). This is because the subject can undergo scrambling to the left of the high adverbial outside $v \mathrm{P}$ without causing an ordering conflict. ${ }^{3}$

\footnotetext{
${ }^{3}$ Following Ko 2014, we call an adverb externally-merged within a $v \mathrm{P}$ a low adverbial, an adverbial externallymerged above $\nu \mathrm{P}$ a high adverbial. This distinction between high and low adverbials has syntactic and semantic consequences. Since low adverbs are merged within $\nu$ Ps, they must be linearized together with the subject when $\nu \mathrm{P}$ undergoes Spell-out. Low adverbs modify the event structure specified within $\nu \mathrm{P}$, so adverbs such as manner, instrumental, and resultative adverbs are categorized into this type. By contrast, high adverbials are linearized separately from the subject in $v \mathrm{P}$ and modify a structure external to the verbal domain, such as TP and CP. Adverbials such as temporal or locative adverbs, speaker-oriented adverbs, and evaluative sentential adverbs belong to the high type. Ko (2014) argues that the distribution of floating numeral quantifiers in Korean are crucially affected by the distinction between high and low adverbials as well as the type of verbal heads which determines transitivity and unaccusativity. Building on Ko 2014, this paper addresses how this distinction of high and low adverbs affect the meaning and grammaticality of proportional quantifiers in Korean.
} 
(29) a. Haksayng-tul-i sey-myeng maykcwu-lul masi-ess-ta.

student-PL-NOM 3-CL beer-ACC drink-PAST-DECL

'Three students drank beer.'

b. *Haksayng-tul-i maykcwu-lul sey-myeng masi-ess-ta.

student-PL-NOM beer-ACC 3-CL drink-PAST-DECL

'Three students drank beer.'

[Ko 2014: 31]

(30)

a. ?*Haksayng-tul-i ilpwule sey-myeng kong-ul pat-ass-ta.

student-PL-NOM deliberately 3-CL ball-ACC receive-PAST-DECL

'Three students received a ball deliberately.'

b. Haksayng-tul-i pwunmyenghi sey-myeng kong-ul pat-ass-ta.

student-PL-NOM evidently 3-CL ball-ACC receive-PAST-DECL

'Evidently, three students received a ball.'

[Ko 2014: 45]

Adverbial floating quantifiers, on the other hand, behave differently from adnominal floating quantifiers. Since adverbial quantifiers are merged outside $v \mathrm{P}$, separately from the host noun, a $v$ P-internal element may intervene between the subject and its associate adverbial quantifier. Ko (2014) shows that a case-marked numeral FQ (floating quantifier) and an exhaustive-marked numeral FQ exhibit this behavior. When the numeral FQ carries a case-marker or an exhaustive marker man ('only'), the quantifiers allow separation from the host noun by a domain-mate as in (31) and by a low adverbial in (32). This sharply contrasts with what we observe with bare numeral quantifiers in (29b) and (30a), which disallow such separation by a $v \mathrm{P}$-domain-mate.

(31) a. Haksayng-tul-i sakwa-lul twu-myeng-i mek-ess-ta.

student-PL-NOM apple-ACC 2-CL-NOM eat-PAST-DECL

'Two students ate apples.'

b. Haksayng-tul-i sakwa-lul twu-myeng-man mek-ess-ta.

student-PL-NOM apple-ACC 2-CL-only eat-PAST-DECL

'Only two students ate apples.'

(32) a. Haksayng-tul-i yelsimhi twu-myeng-i kong-ul cha-ss-ta.

student-PL-NOM diligently 2-CL-NOM ball-ACC kick-PAST-DECL

'Two students kicked a ball diligently.'

b. Haksayng-tul-i yelsimhi twu-myeng-man kong-ul cha-ss-ta.

student-PL-NOM diligently 2-CL-only ball-ACC kick-PAST-DECL

'Two students kicked a ball diligently.'

Building on these arguments, we test how the presence of a low and a high adverbial affects the availability of the non-conservative reading. 


\subsection{Conditions and predictions}

As discussed in Section 4.1, an adnominal quantifier in Korean differs from an adverbial quantifier in that low adverbs such as 'intentionally' and 'quickly' cannot intervene between the host noun and the quantifier. If the floating quantifier involved in the non-conservative construal is an adnominal quantifier, we predict that the non-conservative reading would not be available when a low adverb intervenes. If the floating quantifier is adverbial, on the other hand, we would predict the availability of the non-conservative reading to be not affected by the type of adverbs that intervenes.

The authors' judgments align with the prediction of the adnominal approaches. For example, in (33a), where a high adverb pwunmyenghi ('certainly') intervenes the host noun and the proportional measure noun, both conservative and non-conservative readings are available. However, when a low adverb such as capalcekulo ('voluntarily') or sengsilhi ('diligently') intervenes, the non-conservative reading is no longer available.

a. uysa-tul-i pwunmyenghi isip-phulo chamkahay-ss-ta.

doctor-PL-NOM certainly twenty-percent participate-PAST-DECL

'Certainly, $20 \%$ of the doctors participated.'

[conservative]

'Certainly, $20 \%$ of those who participated were doctors.'

[non-conservative]

b. uysa-tul-I \{capalcekulo / sengsilhi\} isip-phulo chamkahay-ss-ta.

doctor-PL-NOM voluntarily / diligently twenty-percent participate-PAST-DECL

' $20 \%$ of the doctors voluntarily/diligently participated.'

[conservative]

In order to confirm that this contrast is valid and reliable across a larger number of speakers, we designed an experimental study that tests the predictions. We presented four different sentences similar to (33) with a context that was compatible with either a conservative or a nonconservative reading, creating a $2 \times 2$ design between two factors: a) whether the intervening adverbial is high or low ([HIGH], [LOW]), and b) whether the context provided was compatible with a conservative or a non-conservative reading ( $[ \pm \mathrm{CON}])$. Because the prediction in Ko 2014 is based on grammaticality, we asked the participants to not only judge whether the sentence is true or false, but also how natural the sentence is out of a six-point Likert scale.

The four target conditions [HIGH, $+\mathrm{CON}$ ], [HIGH,-CON], [LOW, + CON], and [LOW,-CON] were designed as follows. In the [HIGH] conditions, a high adverbial like surprisingly and certainly appeared in both the context and the target sentence. In the [LOW] conditions, a low adverbial like intentionally and diligently appeared in both the context and the target sentence. The adverbials were added to the context prose because the target sentences sounded odd when the adverbials suddenly appeared out-of-the-blue without contextual support. The target sentences only differed in the choice of the adverb, as shown in (34), with the authors' judgments presented in the gloss. 
(34)

malathon tayhoy-ey uysa-tul-i [adverb] isip-phulo chamkahay-ss-ta.

marathon game-DAT doctor-PL-NOM [adverb] 20-\% participate-PAST-DECL

'([Adverb],) $20 \%$ of the doctors participated ([adverb]) in the marathon.'

a. [HIGH] ... pwunmyenghi ...

certainly

'Certainly, 20\% of the doctors participated in the marathon.'

'Certainly, 20\% of those who participated in the marathon were doctors.'

b. [LOW] ... sengsilhi ...

diligently

' $20 \%$ of the doctors participated in the marathon diligently.'

*'20\% of those who participated diligently in the marathon were doctors.'

The $[ \pm \mathrm{CON}]$ factor was manipulated in the context prose. For example, in the $[+\mathrm{CON}]$ conditions, the participants saw the prose in (35) followed by (35a). Because both of the target sentences contained $20 \%$, the numbers in (35a) is only compatible with the conservative reading of the quantifier, which compares the number of doctors who participated against the total number of doctors. In the [-CON] conditions, on the other hand, the participants saw the prose in (35) followed by (35b), with the numbers compatible only with a non-conservative reading, which compares the number of doctors who participated against the total number of people who participated.

(35) Last summer, a marathon was hosted for free vaccination awareness, and \{certainly\} many people participated \{diligently\}.

a. [ $+\mathrm{CON}]$ : The total number of doctors is 100 , and while a total of 50 people participated in the marathon, the number of doctors who participated was 20.

b. [-CON]: The total number of doctors is 100 , and while a total of 50 people participated in the marathon, the number of doctors who participated was 10.

The conditions that would tease apart the two approaches are the [LOW] conditions: the adverbial approach does not predict the acceptance rate for [LOW] conditions to differ based on the given context $[ \pm \mathrm{CON}]$, while the adnominal approach predicts the acceptance rate to be much lower in the $[-\mathrm{CON}]$ condition than in the $[+\mathrm{CON}]$ condition. The two approaches do not make specific predictions for [HIGH] conditions because high adverbials may appear with either the adnominal or the adverbial quantifier. Thus, we predict the sentences in [HIGH] conditions to be accepted at a high rate unless other factors interfere with the interpretation of high adverbs. 
작년 여름, 예방접종 무상 지원을 위한 마라톤 대회에 분명히 많은 사람들이 참가했다. 전체 의사 숫자가 100 명인데 마라톤 참가자는 총 50 명이고 참가한 의사는 10 명이다.

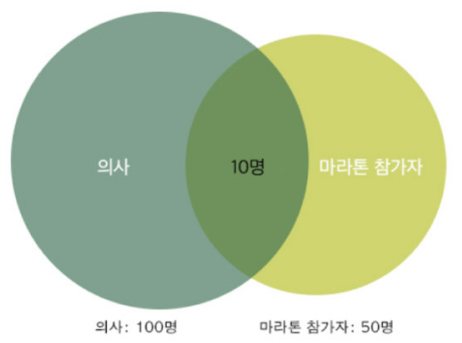

마라톤 대회에 의사들이 분명히 $20 \%$ 참가했다.

위의 문장이 앞의 문맥을 비추어 보아 참인지 거짓인지 판단해 주세요.

Figure 3: A screenshot of the adverb trial in the [HIGH,-CON] condition (English translation of the context and the target can be found in (35) (34), respectively).

\subsection{Participants and Method}

The participants who finished Study 1 were asked to follow a link that led them to Study 2. Sixty out of 61 participants continued onto Study 2. The general methodology of Study 2 was the same as that of Study 1. Because the prompts for this study were more involved, with many numbers appearing in the context, we added Venn Diagrams to help them understand the relations. For example, Figure 3 was shown on the screen with the $[\mathrm{HIGH},-\mathrm{CON}]$ condition of the trial shown in (35b).

Below the context paragraph and the Venn Diagram, the target sentence as in (34) was presented in the middle of the screen. Based on the condition the trial was in, the target sentence contained a high intervening adverb as in (34a) or a low intervening adverb as in (34b). After reading the target sentence, the participants were asked to judge whether the target sentence is true or false based on the presented context. After they responded, a six-point Likert scale appeared, and they were asked to rate how natural the target sentence is based on the context.

The manipulation of the context $([ \pm \mathrm{CON}]$ and the manipulation of the intervening adverb ([HIGH] vs. [LOW]) resulted in four total conditions. There were a total of four test trials and four 
filler trials. The conditions were organized in a Latin-square design for a within-subject study, so each participant saw one of the four conditions once. ${ }^{4}$

\subsection{Results}

Acceptability judgments: All of the target sentences were rated quite low, the average per condition ranging between 2.5 and 3.4 out of 6 . The average ratings per condition are shown in Table 1 . To determine whether the average ratings across different conditions differed significantly from each other, we ran homoscedastic t-tests. In the high adverbial conditions, the average rating was significantly higher in a conservative context than in a non-conservative context $(p=0.004)$. The average ratings did not show any significant difference other than this.

\begin{tabular}{|l|l|l|}
\hline & non-conservative & conservative \\
\hline high adverbial & $2.61(1.33)$ & $3.38(1.51)$ \\
\hline low adverbial & $2.65(1.45)$ & $3.18(1.56)$ \\
\hline
\end{tabular}

Table 1: Average rating (standard deviation) by adverb type and construal.

Truth value judgments: Figure 4 plots the average proportion of 'true' responses by adverb type and construal. There was a main effect of construal, but no main effect of adverb type. For both high and low adverbials, participants were significantly more likely to accept the target sentence when the proportional measure was compatible with a conservative construal $(76 \%$ and $66 \%$ vs. $28 \%$ and $23 \% ; Z=5.091, p<0.001)$.

\subsection{Discussion}

As in Study 1, it is not the case that all sixty-one participants reliably accepted or rejected the target sentences. However, we focus on statistically significant contrasts between the conditions to inform us of the general availability of the readings. We first examine the contrast in the rate of acceptance in the [LOW] conditions. What we see is a significant difference between the conservative and the non-conservative conditions. That is, the rate of accepting a target sentence containing an intervening low adverbial is much higher (66\%) in a conservative context (66\%) than in a non-conservative context (23\%).

\footnotetext{
${ }^{4}$ After running the study, we realized that one of the adverbs we used, twinuckey ('late'), is an aspectual-level adverb, which can be analyzed as a high adverbial in certain accounts, thus is not a clear case of a low adverb. We indeed find that twinuckey behaves differently from other low adverbials in our study. The data we present in this paper includes trials involving this adverbial.
} 


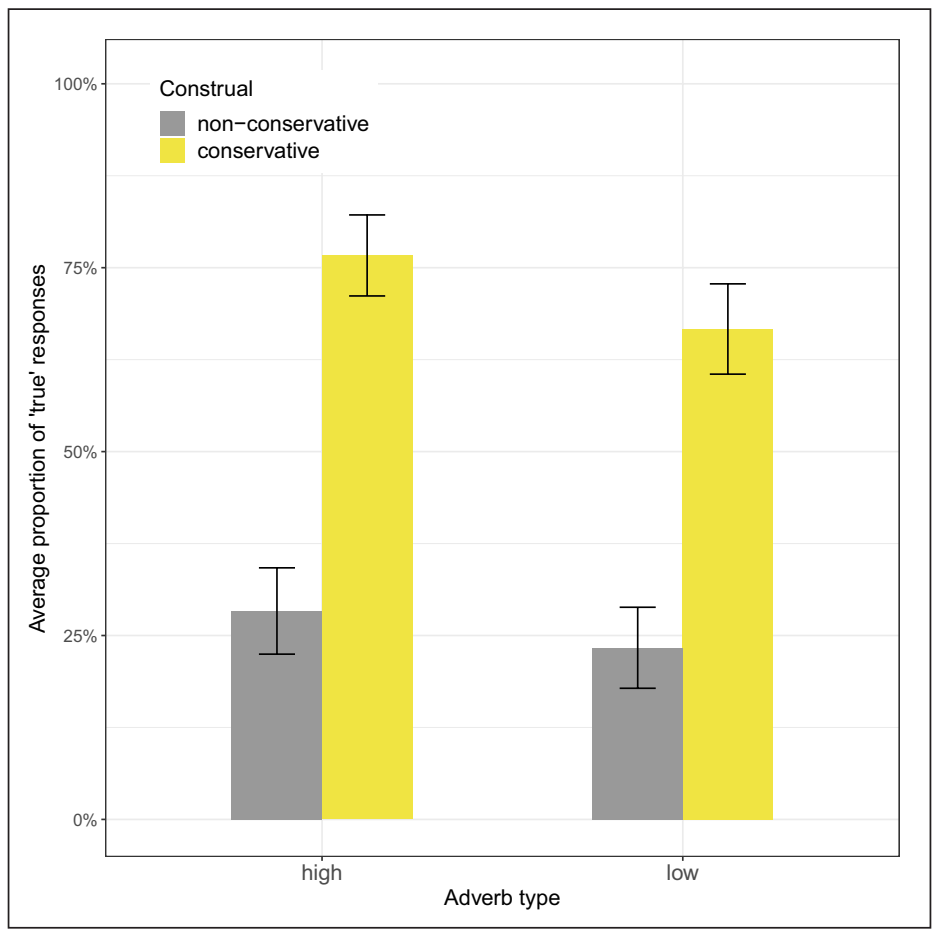

Figure 4: Average proportion of 'true' responses by adverb type and construal.

While we predicted both of the [HIGH] conditions to be rated as true, this was only the case with the $[\mathrm{HIGH},+\mathrm{CON}]$ condition. What we see is that the non-conservative reading is not available even when a high adverbial interferes between the host noun and the quantifier. The exact nature of this low acceptability remains open. We suggest, however, that semantic restrictions for scrambling in Korean could provide a possible explanation for this. Since the high adverb is base-generated above the subject, the subject (the host noun) must undergo scrambling to the left of the high adverb to a position above TP in all our [ + HIGH] contexts. It is noteworthy that scrambled phrases tend to be interpreted definite/specific, which in turn suggests that the host noun would strongly favor a definite/specific reading in the [+ HIGH] conditions. In Study 1 which we presented in Section 3, we observed that definite host nouns are not compatible with a non-conservative reading of a measure phrase. Given that our high adverb conditions favor definite/specific nouns due to scrambling, our high adverb conditions are in fact biased towards a conservative reading, which may explain low acceptability of [+ $\mathrm{HIGH},-\mathrm{CON}]$ contexts. It must be noted, however, that the same issue does not arise for low adverb conditions. The subject is base-generated higher than the low adverb within $\nu \mathrm{P}$, so that intervention by low adverbs does not necessarily involve subject scrambling. Put differently, there is no semantic or syntactic bias to interpret the subject to be definite or specific in low adverb conditions. Thus, the validity of our claim based on low adverb intervention would not be affected by the issues concerning subject scrambling in Korean. 


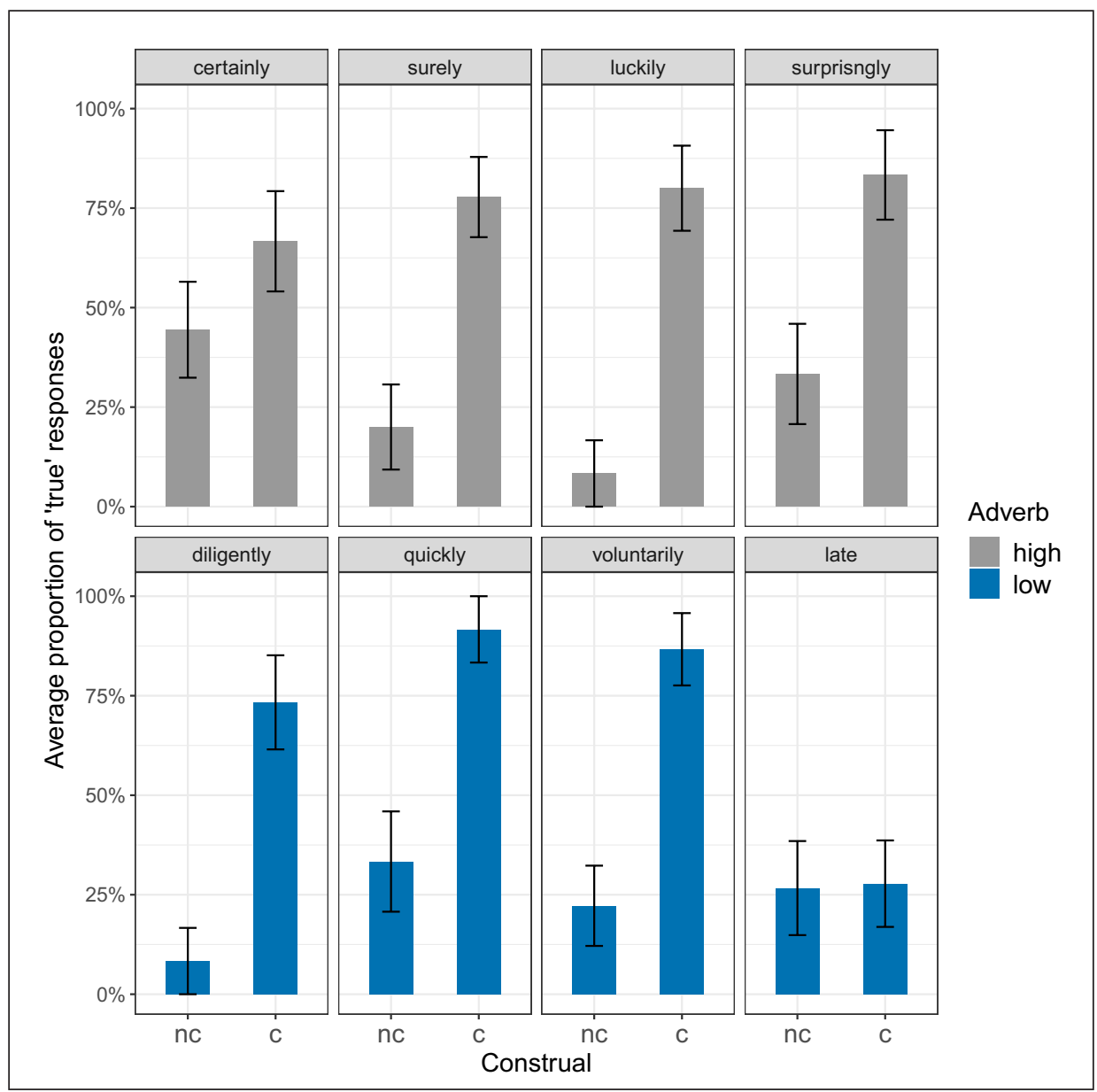

Figure 5: Average proportion of 'true' responses by adverb item.

The average acceptance rates also depend on the specific adverb we used in each of the target sentences. For example, as Figure $\mathbf{5}$ shows, there is some variation across the different lexical items. As mentioned earlier in the paper, it is not clear whether the adverbial twinuckey ('late' or 'belatedly') we categorized under low adverbials is in fact a low adverbial that is merged within $\nu \mathrm{P}$ and linearized together with the subject when $\nu \mathrm{P}$ undergoes Spell-Out. We see that both conservative and non-conservative conditions involving twinuckey show low acceptance rates, unlike the other three low adverbs we tested. It is unclear at this point what this tell us about the nature of the adverb.

Taken together, our results support the adnominal approaches of proportional floating quantifiers: the non-conservative construal does not readily arise when the low adverb intervenes, suggesting that the proportional floating quantifier is base-generated in an adnominal position. 


\section{General Discussion}

Our experimental results in Study 1 and Study 2 from Korean support the adnominal account of non-conservative quantifiers over the competing adverbial account. In this section, we summarize the main findings from the three studies.

\section{Non-conservative readings exist.}

From Study 1, we observe that sentences containing bare host nouns and bare floating quantifiers allow non-conservative readings, with a $38 \%$ and $45 \%$ acceptance rate, respectively. While not at ceiling, the average proportion of 'true' responses for bare host nouns is significantly higher than that for definite-marked host noun (10\%) in Study 1. This serves as the first experimental evidence for the initial observation made in Ahn \& Sauerland 2017.

The acceptance rate might not be at ceiling because of the general oddness of non-conservative construals as reflected by the naturalness ratings. In the Likert scale out of 1 and 6 in Study 2, the average rating for non-conservative sentences was only 3, suggesting that participants found the sentences to be quite odd. Because we presented the truth-value judgment task as a forced binary choice, it is possible that participants rejected the sentence when a parse was not readily available.

\section{Definite host nouns resists non-conservative readings}

Study 1 shows that definite-marked host nouns do not allow non-conservative readings. This restriction against definite host nouns is compatible with adnominal accounts of non-conservative quantifiers where the quantifier moves out of the DP, leaving behind the host noun. On the other hand, this restriction is not explained if the non-conservative reading arises from an adverbial quantification.

Note that Ko (2014) also argues that an adnominal floating quantifier merges to a nonspecific host noun, while an adverbial floating quantifier merges to a pro in the verbal domain. Thus, the blocking of the non-conservative construal with a definite host noun not only confirms the arguments in both of the papers, but also provides empirical support for the presence of adnominal quantifiers that have been proposed independently in syntax and semantics.

3. Low adverbs cannot intervene the host noun and the measure phrase in a nonconservative construal.

Study 2 shows that low adverbs cannot intervene between the proportional quantifier and its host noun in a non-conservative construal. Based on the syntactic diagnostic between adnominal and adverbial floating quantifiers presented in Ko 2014, this intervention effect suggests that the floating quantifier involved in non-conservative construals are adnominal in nature. Semantically, there is nothing blocking the non-conservative reading from arising. Thus, the relatively low rate of acceptance of the non-conservative construal in the presence of an intervening adverb 
provides additional empirical support for the Edge Generalization and the resulting predictions in Ko 2014.

We have seen in Study 2 that target sentences containing intervening high adverbials are also rejected in non-conservative construals. While this is not predicted directly by the diagnostic in Ko 2014, we believe that this might be explained by the definiteness effect that arises from scrambling in Korean. It has been observed that when the subject noun is scrambled to the leftmost position of the sentence, it is interpreted as definite. In our target sentences, the subject nouns appeared in the leftmost position, linearly preceding the high adverb. The scrambling of the subject to the leftmost position might have suggested to the participants that the subject is definite, thus having the same effect as definite-marking the host noun in Study 1. Because bare nouns are unspecified for definiteness in Korean, we were not able to control for the interpretation of bare nouns in terms of definiteness. However, based on our judgments, sentences involving time and locational adverbs such as 'late', 'yesterday', and 'at home' that do not involve subject scrambling in the C-domain readily allow non-conservative readings, thus supporting this possibility.

\section{Conclusion}

In this paper, we presented two empirical studies that support the adnominal analysis of floating proportional quantifiers in Korean. Study 1 established that host nouns involved in non-conservative construals must be non-definite, which is predicted only if the quantifier is derived from the nominal position, and not when it is an adverbial. Study 2 established that low adverbs cannot intervene the floated quantifier and the host noun, thus meeting the criteria for an adnominal floating quantifier based on the diagnostic presented in Ko 2014. We conclude by discussing some implications and remaining questions.

\subsection{Unifying 'most' with proportional quantifiers in Korean}

Our paper provides empirical evidence for adnominal quantifiers that result in a non-conservative reading on the surface. In other words, we show that adnominal quantifiers can result in nonconservative readings when moved out of the DP. This analysis can be extended to taypwupwun ('most') in Korean, which has previously been analyzed as an adverbial quantifier in Park 2007. The predictions of an adnominal account for Study 1 and 2 hold for taypwupwun as well, according to the authors' judgments. For example, when the host noun is definite-marked with a demonstrative and a plural marker as in (36), the non-conservative reading is not available.

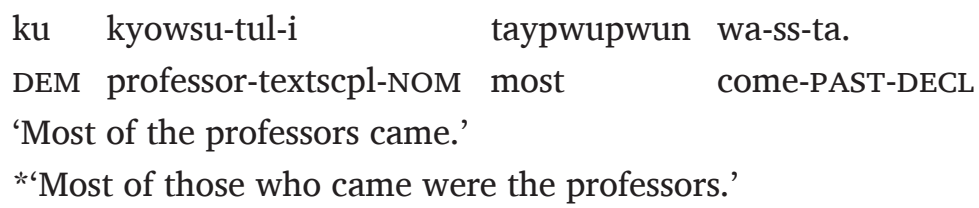

ost

[conservative] [non-conservative] 
Also, when a low adverbial intervenes taypwupwun and its host noun, the non-conservative reading is unavailable as shown in (37).

$$
\begin{aligned}
& \text { kyowsu-ka capalcekulo taypwupwun wa-ss-ta } \\
& \text { professor-NOM voluntarily most came } \\
& \text { 'Most of the professors came voluntarily.' } \\
& \text { *'Most of those who came voluntarily were professors.' }
\end{aligned}
$$$$
\text { [conservative] }
$$

[non-conservative]

Thus, we can uniformly analyze taypwupwun and proportional quantifiers in Korean as adnominal floating quantifiers.

\subsection{Nature of ambiguity in the non-conservative structure}

We have seen in Study 1 that the floating proportional quantifier is ambiguous between a nonconservative and a conservative reading. A questions remain on why such an ambiguity holds for floating proportional quantifiers in Korean. There are at least three possible explanations for this. First, because the value of the restriction is determined by focus, it is possible that the participants interpreted the target sentences as involving a focused VP. This is discussed in both Herburger 1997 and Ahn \& Sauerland 2017 as a possible derivation of a conservative reading. The nature of the online study involving text stimuli does not allow us to control for this or determine whether this was indeed the interpretation made by participants who accepted the conservative reading. Second, it is possible that the participant interpreted the bare floating quantifier to be underlyingly case-marked, thus equating (38) with (39). Case-marked quantifiers are argued to carry a covert pro, thus necessarily resulting in a conservative reading, as the gloss in (39) shows (Ko 2014).

$$
\begin{array}{lllll}
\text { cinan } & \text { hakhoy-ey } & \text { kyoswu-tul-i } & \text { twinuckey } & \text { sasip-phulo tunglokhay-ss-ta. } \\
\text { last } & \text { conference-DAT } & \text { professor-PL-NOM late } & 40-\% & \text { register-PAST-DECL }
\end{array}
$$

$$
\begin{aligned}
& \text { cinan hakhoy-ey kyoswu-tul-i twinuckey sasip-phulo-ka tunglokhay-ss-ta. } \\
& \text { last conference-DAT professor-PL-NOM late } 40-\% \text {-NOM } \\
& \text { 'At the last conference, professors, } 40 \% \text { of them, registered late.' }
\end{aligned}
$$

Lastly, Ko (2014) claims that bare numeral quantifiers, which are normally adnominal in neutral contexts, can be interpreted as adverbials when they receive an exhaustive focus. Specifically, Ko argues that when an exhaustive focus falls on a bare numeral, the numeral is merged on a focus projection separate from the host noun and is not subject to the EG, patterning like other 
adverbial floating quantifiers as shown in (40)-(42). The analysis for exhaustive-marked floating quantifiers also involves a covert pro, thus resulting in a conservative reading.

a. Haksayng myech-myeng-i khemphyuthe chayk-ul sass-ni? student how.many-CL-NOM computer book-ACC bought-Q 'How many students bought the computer book?'

b. ?Haksayng-i kukes-ul twu-myeng sa-sse. Student-NOM it-ACC 2-CL buy-PAST-DECL 'Two students bought it.'

[Kang 2002: 387]

(41) Haksayng-i khemphyuthe-lul twu-myeng, phulinthe-lul sey-myeng sassta. student-NOM computer-ACC 2-CL printer-ACC 3-CL bought 'Two student bought computers and three students bought printers.' [Kang 2002: 387]

(42) Haksayng-tul-i maykcwu-lul sey-myeng motwu masi-ess-ta. student-PL-NOM beer-ACC 3-CL all drink-PAST-DECL

'All three students drank beer.'

This potential ambiguity of bare numerals explains rather unexpected judgment variations concerning the EG in some focal contexts, and can be extended to account for the ambiguity observed in our studies. In particular, it is possible that the participants were interpreting the target sentences as carrying exhaustive focus on the quantifier.

\subsection{Why are non-conservative adnominal quantifiers so rare?}

We have argued in this paper that the non-conservative reading resulting from a floating quantifier is adnominal. Adnominal quantifiers that result in a non-conservative reading are not so common across languages, and require a very specific syntactic structure and focus in many languages as shown in Herburger 1997 and Ahn \& Sauerland 2017. A question that is raised immediately is why this type of quantifier is so rare in natural languages. One possibility is that this is due to semantic and syntactic economy constraints. An event modification through an adverbial quantifier usually results in a truth-conditionally identical proposition, and is often syntactically simpler. Adnominal FQs necessarily involve movement of the host noun, which can be restricted by various conditions in syntax. By contrast, adverbial FQs can be freely merged in the VP domain as long as its semantic type can be matched with the verbal domain. Adjunction is a free operation in syntax whereas movement requires morphological or featural triggers to be licensed. This might explain why, even in languages that allow adnominal floating quantifiers, stranding of an adnominal quantifier is rare compared to that of an adverbial quantifier (Ko 2014). 


\subsection{Implications on non-conservative quantifiers}

The results of our studies have implications on non-conservative quantifiers identified in previous literature. While Herburger (1997) and Ahn \& Sauerland (2017) both discuss the possibility of deriving a non-conservative reading out of a quantifier through movement and association with focus, there has not been any overt, empirical evidence for this. Our study confirms that the floating quantifier structure involved in non-conservative construals in Korean are indeed derived through a movement from the nominal domain, thus forming the first set of empirical evidence for the adnominal accounts of non-conservative quantifiers.

While we have combined the discussion of the two adnominal accounts into one category in this study, the two analyses do have nontrivial differences. For example, Herburger (1997) crucially relies on the non-conservative quantifiers involving D-raising rather than $Q R$, while Ahn \& Sauerland (2017) argue that non-conservative proportional quantifiers QR to take clausal scope. It is an open question whether the two kinds of movement can be teased apart using data from Korean. This is left for future investigation. 


\section{Abbreviations}

ACC $=$ accusative, $\mathrm{CL}=$ classifier, $\mathrm{CONJ}=$ conjunction, $\mathrm{DAT}=$ dative, $\mathrm{DECL}=$ declarative, GEN $=$ genitive, LOC $=$ locative, $\mathrm{NOM}=$ nominative, $\mathrm{PL}=$ plural, $\mathrm{TOP}=$ topic

\section{Ethics and consent}

The experimental study conducted was approved by the relevant Institutional Review Board (\#Pro2020001850). Informed consent was obtained from the participants at the very beginning of the study, when the participants were asked to read through the study description and continue on to the study if they agree to the terms. No identifiable information was collected during the study. For the distribution of coffee vouchers, a separate survey was made to collect only their mobile numbers, so that no link could be made between the contact information and their responses. The mobile numbers were deleted immediately after the vouchers were sent out.

\section{Acknowledgements}

The authors wish to thank the participants of our online studies for their time.

\section{Competing interests}

The authors have no competing interests to declare.

\section{References}

Ahn, Dorothy. 2017. Definite and demonstrative descriptions: a micro-typology. In Erlewine, Michael Yoshitaka (ed.), Proceedings of Generative Linguistics in the Old World in Asia 11, vol. 1, 33-48. MIT Working Papers in Linguistics.

Ahn, Dorothy \& Davidson, Kathryn. 2018. Where pointing matters: English and Korean demonstratives. In Hucklebridge, Sherry \& Nelson, Max (eds.), Proceedings of the Forty-Eighth Annual Meeting of the North East Linguistic Society, vol. 1, 15-24. GLSA, University of Massachusetts.

Ahn, Dorothy \& Sauerland, Uli. 2017. Measure constructions with relative measures: Towards a syntax of non-conservative construals. The Linguistic Review 34(2). 215-248. DOI: https://doi. org/10.1515/tlr-2017-0001

Ahn, Dorothy \& Snedeker, Jesse. 2021. Early acquisition of plural morphology in a classifier language: Data from Korean 2-4 year olds. Language Learning and Development. DOI: https://doi. org/10.1080/15475441.2021.1922280

Barwise, Jon \& Cooper, Robin. 1981. Generalized quantifiers and natural language. In Kulas, J. \& Fetzer, J. H. \& Rankin, T. L. (eds.), Philosophy, Language, and Artificial Intelligence. Studies in Cognitive Systems, vol. 2, 241-301. Springer. DOI: https://doi.org/10.1007/978-94-009-2727-8_10

Beck, Sigrid \& Kim, Shin-Sook. 1997. On wh-and operator scope in Korean. Journal of East Asian Linguistics 6(4). 339-384. DOI: https://doi.org/10.1023/A:1008280026102 
Cho, Jacee. 2016. The acquisition of different types of definite noun phrases in L2-English. International Journal of Bilingualism 21(3). 367-382. DOI: https://doi. org $/ 10.1177 / 1367006916629577$

Chomsky, Noam. 2001. Derivation by phase. In Kenstowicz, Michael (ed.), Ken Hale: A Life in Language, 1-52. Cambridge, Mass: MIT Press.

Cohen, Ariel. 2001. Relative readings of many, often, and generics. Natural Language Semantics 9(1). 41-67. DOI: https://doi.org/10.1023/A:1017913406219

Doetjes, Jenny Sandra. 1997. Quantifiers and selection: On the distribution of quantifying expressions in French, Dutch and English. Leiden, the Netherlands: Leiden University dissertation.

Fitzpatrick, Justin Michael. 2006. The syntactic and semantic roots of floating quantification. Cambridge, MA: Massachusetts Institute of Technology dissertation.

Fox, Danny. 2002. Antecedent-contained deletion and the copy theory of movement. Linguistic Inquiry 33(1). 63-96. DOI: https://doi.org/10.1162/002438902317382189

Fox, Danny \& Pesetsky, David. 2005. Cyclic linearization of syntactic structures. Object Shift in Scandinavian, Theoretical Linguistics 31(1-2). 1-45. DOI: https://doi.org/10.1515/thli.2005.31.12.1

Heim, Irene \& Kratzer, Angelika. 1998. Semantics in Generative Grammar, vol. 13. Oxford: Blackwell.

Herburger, Elena. 1997. Focus and weak noun phrases. Natural Language Semantics 5(1). 53-78. DOI: https://doi.org/10.1023/A:1008222204053

Ishii, Yasuo. 1998. Floating quantifiers in Japanese: NP quantifiers, VP quantifiers, or both? Researching and Verifying on Advanced Theory of Human Language 2. 149-171.

Kang, Beom-Mo. 2002. Categories and meanings of Korean floating quantifiers - with some references to Japanese. Journal of East Asian Linguistics 11. 375-398. DOI: https://doi. org/10.1023/A:1019967311110

Keenan, Edward L \& Stavi, Jonathan. 1986. A semantic characterization of natural language determiners. Linguistics and Philosophy 9(3). 253-326. DOI: https://doi.org/10.1007/ BF00630273

Kim, Chonghyuk. 2005. The Korean plural marker tul and its implications. Newark, DE: University of Delaware dissertation.

Ko, Heejeong. 2005. Syntactic edges and linearization. Cambridge, MA: Massachusetts Institute of Technology dissertation.

Ko, Heejeong. 2007. Asymmetries in scrambling and cyclic linearization. Linguistic Inquiry 38. 49-83. DOI: https://doi.org/10.1162/ling.2007.38.1.49

Ko, Heejeong. 2014. Edges in syntax: Scrambling and cyclic linearization, vol. 50. Oxford: OUP. DOI: https://doi.org/10.1093/acprof:oso/9780199660261.001.0001

Kobuchi-Philip, Mana. 2003. Distributivity and the Japanese floating numeral quantifier. New York, NY: The City University of New York dissertation. 
Kobuchi-Philip, Mana. 2007. Floating numerals and floating quantifiers. Lingua 117. 814-831. DOI: https://doi.org/10.1016/j.lingua.2006.03.008

Kuroda, Shige-Yuki. 1983. What can Japanese say about government and binding? In Barlow, Michael \& Flickinger, Daniel P. \& Westcoat, Michael T. (eds.), Proceedings of WCCFL 2, 153-164. Stanford Linguistics Association, Stanford University.

Kwon, SongNim \& Zribi-Hertz, Anne. 2004. Number from a syntactic perspective: Why plural marking looks 'truer' in French than in Korean. Empirical Issues in Formal Syntax and Semantics 5. 133-158.

Lee, Chungmin. 1992. Definite/specific and case marking in Korean. Theoretical Issues in Korean Linguistics, 325-341.

Park, Yugyeong. 2007. A study on the semantic characteristics of the proportional quantifier floating in Korean. Seoul, Korea: Seoul National University MA thesis.

Pasternak, Robert \& Sauerland, Uli. 2022. German measurement structures: Case-marking and non-conservativity. The Journal of Comparative Germanic Linguistics.

Roberts, Craige. 2003. Uniqueness in definite noun phrases. Linguistics and Philosophy 26(3). 287-350. DOI: https://doi.org/10.1023/A:1024157132393

Romero, Maribel. 2015. The conservativity of many. In Brochhagen, Thomas \& Roelofsen, Floris \& Theiler, Nadine (eds.), Proceedings of the 20th Amsterdam Colloquium, 20-29.

Sauerland, Uli. 2004. The interpretation of traces. Natural Language Semantics 12(1). 63-127. DOI: https://doi.org/10.1023/B:NALS.0000011201.91994.4f

Sohn, Ho-Min. 1994. Korean (Descriptive Grammars). London/New York: Routledge.

Sportiche, Dominique. 1988. A theory of floating quantifiers and its corollaries for constituent structure. Linguistic Inquiry 19. 425-449.

Ueda, Masanobu. 1990. Japanese phrase structure and parameter setting. Amherst, MA: University of Massachusetts Amherst dissertation.

von Fintel, Kai. 1997. Bare plurals, bare conditionals, and only. Journal of Semantics 14(1). 1-56. DOI: https://doi.org/10.1093/jos/14.1.1

von Fintel, Kai \& Keenan, Edward L. 2018. Determiners, conservativity, witnesses. Journal of Semantics 35(1). 207-217. DOI: https://doi.org/10.1093/jos/ffx018

Westerståhl, Dag. 1985. Logical constants in quantifier languages. Linguistics and Philosophy 8(4). 387-413. DOI: https://doi.org/10.1007/BF00637410

Zehr, Jeremy \& Schwarz, Florian. 2018. PennController for Internet Based Experiments (IBEX).

Zuber, Richard. 2004. A class of non-conservative determiners in Polish. Lingvisticae Investigationes 27(1). 147-165. DOI: https://doi.org/10.1075/li.27.1.07zub 